\title{
SAMENESS, DIFFERENCE AND ENVIRONMENTAL CONCERN IN THE METAPHYSICS AND ETHICS OF SPINOZA AND CHAN BUDDHISM
}

\author{
MICHAEL HEMMINGSEN
}

\begin{abstract}
In this paper I contrast the metaphysical philosophies of Benedict de Spinoza and the 'sudden enlightenment' tradition of Chan Buddhism. Spinoza's expressivist philosophy, in which everything can be conceived via a lineage of finite causes terminating in substance as a metaphysical ground of all things, emphasises the relative sameness of all entities. By contrast, Chan's philosophy of emptiness, which rests on the dependent co-origination of all entities, renders such comparison fundamentally meaningless. Having no source beyond dependent co-origination to generate a thing's distinct nature leads to a metaphysics in which, rather than being relatively similar or different, all things are at one and the same time absolutely the same and absolutely distinct. As a result, Spinoza grounds ethics wholly is sameness or similarity, whereas Chan transcends the dichotomy of sameness and difference and offers an environmental ethics grounded simultaneously in absolute sameness and absolute difference. As a result, in Spinoza's case, the dissimilarity between human beings and the nonhuman world places limits on our concern for it. In Chan Buddhism, however, insight into the emptiness of all phenomena leads to a concern for all entities in their suchness, regardless of whether they are similar or different to human beings. As such, I argue that Chan is in a better position than Spinoza to develop a robust environmental ethic.
\end{abstract}

Keywords: Buddhism, Chan (禪), ethics, metaphysics, Spinoza

\section{INTRODUCTION}

In this paper I contrast the metaphysical philosophies of Benedict de Spinoza and the "sudden enlightenment" tradition of Chan (禪) Buddhism. ${ }^{1}$ Both systems hold that the nature of a thing should be understood via that through which it can be conceived. However, Spinoza's expressivist philosophy, in which everything can be conceived via

HEMMINGSEN, MICHAEL: Visiting Assistant Professor, Tunghai University, Taiwan, ROC. Email: mhemmingsen@thu.edu.tw

\footnotetext{
${ }^{1}$ For convenience, I will refer to "Chan Buddhism", though it should be noted that the "sudden enlightenment" is, though dominant, not the entirety of that school.
} 
a "lineage" of finite causes, terminating in substance as a metaphysical ground of all things, emphasises the relative sameness of all things. That is, while things in the world are distinct from each other as particular expressions of infinite substance, they can be said to be similar or different depending on the specific causes through which they are conceived. By contrast, Chan's philosophy of emptiness, which rests on the dependent co-origination of all entities, renders such comparison fundamentally meaningless. Having no source beyond dependent co-origination generating an entity's distinct nature leads to a metaphysics in which, rather than being relatively similar or different, all things are at one and the same time absolutely the same and absolutely distinct.

These two metaphysical positions have clear implications for environmental ethics. In Spinoza's case, contra how he has been used by some deep ecologists, the dissimilarity between human beings and the non-human world places limits on our concern for it. In Chan Buddhism, however, insight into the emptiness of all phenomena leads to a concern for all entities in their suchness, whether or not they are similar or different to human beings. As such, I argue that Chan is in a better position than Spinoza to develop a robust environmental ethic.

In the first part of the paper, I outline the metaphysical systems of Spinoza and Chan, followed by a comparison of the two systems in terms of their views on sameness and difference. In the second part, I discuss the ethical philosophies that arise from the distinctive metaphysics of Spinoza and Chan, followed by a discussion of how their disagreement over sameness and difference informs their views. Finally, I examine the implications of this disagreement in the context of environmental philosophy.

\section{PART I}

\subsection{SPINOZA'S METAPHYSICS}

For Spinoza, there is nothing beyond substance. Substance is the only thing that exists in and of itself, or through itself. Everything else that exists can be thought of as the properties of substance: they inhere in it in a similar way that the property of colour inheres in a physical object. Just as colour cannot exist in the abstract, i.e., without belonging to a particular physical object, things in the world can only exist as a modification of the singular substance.

Substance is only ever accessible to us through its attributes, of which we can know only two: the attribute of extension and the attribute of thought. The attributes of extension and thought are infinite 'after their kind.' That is, insofar as they are one way that substance can be conceived, each attribute is limited by each other attribute (if something is extended, it is not thought, and vice versa). Attributes do not therefore have the absolute infinity of substance. However, they are unlimited in the sense that each attribute, in its own kind, extends infinitely. Nonetheless, attributes are not a part of substance. Attributes have an epistemological rather than ontological existence: they are ways through which we can know substance, but they have no independent existence of their own. 
Unlike attributes, finite things in the world $d o$ exist ontologically, if not independently. The things that we encounter in the world are called 'modifications' or 'modes' of substance. Modes ultimately do not have an existence outside substance, in that they have no self-subsisting reality. They are "that which is in another through which it is also conceived" (Spinoza 1994, 1d5); there is always, by definition, something logically prior to modes. However, this does not mean that they are in any way illusory. Colour, for example, arguably cannot be conceived except through objects in which the colour property inheres. Similarly, modes cannot be conceived except through the substance in which it inheres. Nevertheless, colours are no less real for this, and nor are modes.

However, as they are known to us, modes are never modes of substance directly but are always conceived through one attribute or another. In other words, a mode is always apprehended as an extended thing or a mental thing, but never just as a thing. Yet, because attributes do not have any substantive reality - they are merely that through which substance is conceived - then everything is both an extended thing and a mental thing simultaneously: the only question is through which attribute we are perceiving it. In other words, for every table, there is the thought of that table; for every thought you have, there is a corresponding modification in your body that exactly parallels it. The physical table and the thought of the table are the very same table, but we can only come to know that 'bare' table either as an extended object or as the thought of the table. Thought and extension are therefore two ways we can know the very same table. As Spinoza puts it, "The order and connection of ideas is the same as the order and connection of things" (1994, 2p7); "a mode of extension and the idea of that mode are one and the same thing, but expressed in two ways" (1994, 2p7s).

The nature of individual modes - their particular qualities and characteristics constitute that thing's essence. In turn, a thing's essence is constituted by the conditions that gave rise to it: in other words, its causes. However, as Michael Dela Rocca argues, we should understand the term 'cause' in Spinoza in a particular way. To say that a thing is caused by some other thing should be understood as saying that it is conceived through that thing $(2011,18)$. Hence, conception is more fundamental than causation; or, to put things another way, causation is a kind of conception.

By understanding causation as conception, we can square some seemingly contradictory aspects of Spinoza's metaphysics. Spinoza clearly states that modes are caused by substance. For instance, he says that "God is the efficient cause, not only of the existence of things, but also of their essence" (1994, 1p25). At the same time, Spinoza says that,

Every singular thing, or any thing which is finite and has a determinate existence, can neither exist nor be determined to produce an effect unless it is determined to exist and produce an effect by another cause, which is also finite and has a determinate existence; and again, this cause also can neither exist nor be determined to produce an effect unless it is determined to exist and produce an effect by another, which is also finite and has a determinate existence, and so on, to infinity $(1994,1 \mathrm{p} 28)$. 
That is, finite things can only be caused to exist by other finite things.

But substance is infinite. If finite things can only be caused to exist by other finite things, how can substance be the cause of the finite modes? The answer is that 'cause' is understood here as a logical condition rather than a spatio-temporal one. A cause is therefore anything by which a mode would otherwise not be what it is. From other finite modes, a mode gains certain finite determinate qualities. But finite modes do not have in their essence that they exist. In other words, we can easily conceive of any finite thing not existing. What is responsible for a finite thing existing, then, is not itself; nor its finite causes (which can also be conceived as not existing); but rather substance, which is the only thing that has existence as a part of its essence. In Spinoza's words,

God is the cause of the being of things. For - whether the things exist or not - so long as we attend to their essence, we shall find that it involves neither existence nor duration. So their essence can be the cause neither of their existence nor of their duration, but only God [substance], to whose nature alone it pertains to exist [can be the cause] (1994, 1p24c).

To say that substance causes finite modes, then, is to say that a modes existence is logically given by substance. We can only conceive of a mode existing by conceiving of substance as logically prior to it. By the same token, any other determinate quality a mode has is also 'caused' by the finite modes prior to it, in the sense that we can conceive of that mode having the properties it does only through those other finite modes. Hence, 'conceive' and 'cause' are equivalent: to say that something is caused by another thing is merely to say that it is conceived through that thing. When we conceive of a finite mode through another finite mode, that conception looks more like what we typically understand as causation, e.g., a spatio-temporal relationship, and when we conceive it through infinite substance, it is a logical condition.

For Spinoza, then, the essence of any finite thing is always given in terms of other things. Nothing (except substance) is what it is by virtue of itself, but rather always by virtue of things other than itself. To fully account for any finite mode, "we have to appeal to an infinite nexus of causes - the entire continuum of physical being" (Lord $2010,44)$. At the same time, that infinite continuum of finite things is ultimately conceived through substance itself. Substance expresses its essence - existence - in all finite modes. Once we have a full accounting of all the conditions that have produced any finite thing - including substance - we can then know what that thing is, e.g., its properties, capacities and so on.

What is particularly worth noting in this picture is its unidirectional nature. Substance expresses itself in modes, but modes do not in turn express themselves in substance. A finite mode is conceived through finite modes that have caused it, but those causes are not in turn conceived through the finite mode they give rise to. In other words, while $\mathrm{B}$ is conceived through $\mathrm{A}, \mathrm{A}$ is not conceived through $\mathrm{B}$. We always move from $\mathrm{A}$ to $\mathrm{B}$, and never the other way around. For this reason, even though things are always conceived through other things, the essence of modes can be 'full,' in the sense that their causes are determinative of their specific, individual character. This is quite different, as we will see, from the bi-directional causation/conception of Chan. 


\subsection{CHAN METAPHYSICS}

Both Spinoza and Chan Buddhism see things in the world as being nothing more than their causes. In that respect, both schools of thought are strikingly similar. However, Chan metaphysics draws significantly on the Mādhyamika school of Buddhism, who are famously concerned with the rejection of essence, or self-nature (Sa.: svabhāva/Ch.: zi-xing 自性). According to the Mādhyamika philosopher, Nāgārjuna, nothing in the world can be considered a separate, individual and self-subsisting entity. Instead, everything is "empty" (Sa.: śünyatā/Ch.: kong 空). In other words, nothing has an inherent, essential or substantial existence.

While Spinoza's metaphysics sees everything as emanating from a shared source, Chan instead posits the doctrine of dependent co-origination (Sa.: pratityasamutpāda/Ch.: yuan-qi 緣起). Dependent co-origination holds, like Spinoza, that everything that exists is constituted by the other things that have caused it. However, Chan differs from Spinoza in that it does not think that there is a deeper or further source that causes things. Instead, things in the world cause each other, e.g., dependent co-origination. As a result, things 'inter-be' with everything else in the world. As Masao Abe puts it, we

know that fire requires fuel to burn. However, can fire ever exist without fuel? It cannot. And can fuel exist without fire? We may be tempted to say yes, but Buddhism asks us to pause for a moment before we do so. A $\log$ of wood cannot qualify as fuel if the phenomenon of fire did not exist. A log of wood would then remain merely a log of wood - it is the possibility of using it for fire that makes it into fuel. Hence it possesses no svabhāva or self-nature as fuel $(1997,43)$.

It is worth noting here two things: first, the relationship between fire and fuel is bidirectional. For Spinoza, fuel might cause fire, but fire does not in turn cause fuel. But for Chan, causation is reciprocal. Second, seeing the relationship of fire to fuel as mutual treats causation and conception as equivalent, just as Spinoza does. After all, it would be strange to claim that fire is causally responsible for fuel if we use 'cause' as 'spatio-temporal cause.' Fire does not spatio-temporally cause fuel. However, since fuel is not 'fuel' without fire, then we can say that fire is part of the conception of fuel. In other words, we cannot understand something as fuel without conceiving it through fire. In that more expansive sense of 'cause,' then - a sense not wholly dissimilar to Spinoza's view - fire causes fuel.

However, what can also be noted here is that if we are to say that fuel cannot be understood as fuel without fire, clearly there is something there that already that can be understood as fuel, once we conceive it in relationship to fire. That is, what we call fuel is there as a unique particular. Unlike Spinoza's view, which we might refer to by comparison as 'dependent origination,' a dominant view amongst Chan Buddhists is that dependent co-origination is an epistemological thesis rather than an ontological one. In other words, by realising that what we take to be the self-nature - the essence - 
of a thing is nothing more than what arises when unique particulars are conceived through other unique particulars, we can see that there is really nothing (though not "no thing') there; there are only unique particulars. If fuel's nature is given by fire, and fire's nature is given by fuel, then ultimately neither fuel nor fire are grounded. There is nothing that has the nature of fuel, and there is nothing that has the nature of fire: we need one of the two to be in some way more ontologically fundamental to get such descriptions off the ground, and the dependent co-origination of fuel and fire makes this impossible.

Chan practitioners therefore attempt to see beyond the apparent self-nature of things to their emptiness. Beyond that emptiness are the things themselves, in their unique particularity. A famous discourse by Chan master Ch'ingyuan Wei-hsin describes this process:

Thirty years ago, before I began the study of Zen, I said, 'Mountains are mountains; waters are waters.' After I got insight into the truth of Zen through the instruction of a good master, I said, 'Mountains are not mountains; waters are not waters.' But now, having attained the abode of final rest [that is enlightenment], I say, 'Mountains are really mountains; waters are really waters' (Quoted in Abe 1985, 4).

In other words, at the first, untutored stage, we see things as having self-nature. Once we realise that they are dependently co-originating, we come to understand that those self-natures have no real basis. But as a result of realising the emptiness of things, we can in turn come to see them as they are. In other words, we no longer see mountains as "mountains", but rather merely as "that", i.e., as the unique particular that it is. As a result, calling things in the world "empty" is not nihilism. To refer to something as "empty" is not to say that it does not exist. After all, we cannot say "that thing is empty" unless there is a "that thing" to which we are referring. As Jay L. Garfield puts it, "to be empty of essence is not to be empty of existence. Instead, [for Chan Buddhists] to exist is to be empty" $(2009,27)$. Rather, Chan denies that there is anything more to the things we encounter than their 'suchness' (Sa.: tathatā/Ch. Xin-dai 信代); they are simply what they are. As Chan patriarch Huineng puts it,

You may want to say it is real, yet no defining characteristics can be found; you may want to say it is unreal, yet it functions without interruption. Therefore it cannot be said not to exist, yet cannot be said to exist $(1998,119)$.

For this reason, Masao Abe describes emptiness as "a fullness of particular things and individual persons functioning in their full capacity and without mutual impediment" $(1985,211)$. Emptiness may deny the self-nature of things, but in achieving the understanding that things are empty, instead we come to see them in their fullness and particularity.

The realisation of emptiness is at the same time a realisation that all concepts we use to understand things are misleading. This is known as the 'doctrine of noappearances.' For Chan, we ought to be "apart from labels and appearances” (Huineng 
1998, 144); we should realise that concepts are something that arise from the human mind, not from reality itself. Conceptual knowledge of this kind is not just mistaken, but also leads to inappropriate attachment. In the Chan view, to understand a thing through a concept is to objectify it. In other words, it is viewing that thing through a lens which causes us to attend to some aspects of it, while concealing other aspects. Since we mistakenly take concepts to be in the self-nature of things, we then take that partial and one-sided view of the thing to be the thing itself: to be its essence. Conceptual knowledge therefore means knowing the thing "not in its totality but only so far as it is objectified" (Abe 19979, 30). In other words, concepts conceal rather than reveal the nature of the thing.

At the same time, "emptiness" itself is a concept. Hence, the Chan practitioner is encouraged to empty emptiness. This means moving beyond the reification of emptiness, i.e., no longer seeing things as having an 'empty' self-nature, since an empty self-nature is still a self-nature. The reification of emptiness is the second stage: "Mountains are not mountains; waters are not waters." Emptying emptiness takes us to the third stage: "Mountains are really mountains; waters are really waters." Chan practitioners therefore hold that an appreciation of true emptiness is seeing things as neither empty nor not empty. In Masao Abe's words, "Emptiness that is objectified and conceptualized must be emptied" (1997, 48). As Nāgārjuna puts it in his Mulamadhyamakakārikā,

Emptiness is taught by the conquerors as the expedient to get rid of all [metaphysical] views. But those for whom emptiness is a [metaphysical] view have been called incurable (Siderits and Katsura 2013, 13:8).

Similarly, Huineng states that,

If on the outside you are deluded you cling to form; if on the inside you are deluded you cling to emptiness. If within form you are apart from form and within emptiness you are separated from emptiness, then within and without you are not deluded $(2012,166)$.

\subsection{DISCUSSION}

The metaphysical systems of Spinoza and Chan do have certain things in common; for instance, their view that a thing's nature is constituted by the things through which it is conceived. However, two major differences - the difference between ontological and epistemological ideas of conception and whether conception is uni-directional or bidirectional - leads to divergent positions.

Spinoza holds, as Chan does, that all things are unique. But the explanation of that uniqueness is importantly different. For Spinoza, a thing's essence is due to the particular causes that give rise to it: its dependent origination. Since no two things can ever have exactly the same set of causal antecedents, then "no two things share the same essence" (Della Rocca 2008, 94), i.e., they are unique. But this is a relative uniqueness. No two things can share exactly the same causal conditions, but they can 
nonetheless have conditions in common. In this sense, modes can share a 'lineage.' For instance, all living human beings share an ancestor. In that sense, all human beings share a cause. Since the essence of a thing is determined by its cause, then to the extent that we share the same cause, we have the same essence. This is a result of Spinoza's 'expressive' metaphysics, in which substance articulates itself in modes in a unidirectional way. All modes are united in substance, but nonetheless each mode is one thread of substance's self-expression; it is the result of a particular series of finite causes. Those threads can be closer or further from each other, in the sense that they can share a lineage to one extent or another, and as a result the essence of modes can be more or less similar.

By contrast, while in Chan as well a thing is in its causes, unlike Spinoza we cannot trace these causes back to a single infinite substance. In Spinoza, we can conceive of $\mathrm{A}$ in terms of B, then B in terms of C, and so on up the infinite chain of finite modes, and ultimately to substance as a grounding. But in Chan, while A is conceived in terms of $\mathrm{B}$, there is not a more basic thing by which $\mathrm{B}$ gains it nature. Instead, B gains its 'nature' by being conceived through $\mathrm{A}$. But if $\mathrm{A}$ is conceived through $\mathrm{B}$, and $\mathrm{B}$ is conceived through $\mathrm{A}$, neither can have a nature that is. If everything about $\mathrm{A}$ is given to it by B, and everything about B given to it by A, then at what point can we say that either A or B are meaningfully distinguishable - conceptually - from the other? The nature of $\mathrm{A}$ is not the grounds of $\mathrm{B}$, because its nature is itself grounded by B. What it gives to $\mathrm{B}$ it takes from $\mathrm{B}$ in the first place. Hence, nothing is truly being given or taken.

Due to dependent co-origination, then, Chan disallows comparison entirely. Nothing can be like any other thing to any extent whatsoever. Once we realise that things are empty of essence, Chan thinks that we will come to realise that all things are unique. It is only through the mistaken reification of things in conceptual thought that we think any two things can be compared. Hence, the Chan view is one of absolute difference between things. At the same time, to describe things as 'absolutely different' is to fall into the same trap as reifying emptiness. To call things 'different' is itself a form of comparison, of reification. But nothing in Chan can be in any way meaningfully compared to any other. Hence, at the same time as being absolutely different, we should also come to understand all things as absolutely the same in their suchness. In other words, being only themselves and nothing more, things are neither similar to, nor different from, other things. They are the same in their incomparability, and different in their uniqueness. Neither term on its own gives the right picture: to really appreciate the suchness of things, we need to hold both the idea of absolute sameness and that of absolute difference together at the same time, while also realising that both terms are misleading. To put things another way, in Chan similarity and difference are themselves conceptual terms that are transcended. In being transcended, they are no longer opposites. Paradoxically, then, the fact that things are absolutely the same as each other is equivalent to saying that they are absolutely different.

In short, Spinoza's expressivist view in one of comparison - of relative sameness and difference. On the other hand, the Chan philosophy of emptiness empties out the idea of comparison itself, leading to a perspective in which absolute sameness and absolute difference are identical. 


\section{PART II: ETHICS}

The metaphysics of Spinoza and Chan have direct implications for their moral philosophies. In this second half of the paper, I outline the ethical views of Spinoza and Chan, with a focus on how they are continuous with their metaphysics.

\subsection{SPINOZA'S ETHICS AND MORAL PHILOSOPHY}

For Spinoza, if composite entities, such as human beings,

whether of the same or of different size, are so constrained by other bodies that they lie upon one another, or if they so move, whether with the same degree or different degrees of speed, that they communicate their motions to each other in a certain fixed manner, we shall say that those bodies are united with one another and that they all together compose one body or individual, which is distinguished from the others by this union of bodies (1994, 2p1313a2def.).

All modes, both composite and simple, are capable of doing certain things. Composite entities are more complex than simple ones, and as a result they can affect other things and be affected by them in more ways. Since we live in a world of modes, the power of any mode to act is constrained by the power of other modes whose nature is to act in a way contrary to that mode. In other words, every entity that exists is limited in what it can do due to the power of other things and the qualities substance confers on all modes in a given attribute (what Spinoza calls 'infinite modes', but which we can usefully think of as the laws of nature).

Spinoza identifies two forms of behaviour that modes can engage in. First, modes can express their own essence: they can act. Second, they can be caused by another mode to behave in a certain way, what Spinoza refers to as being "passive".

To say that a mode acts is at the same time to say that it is the adequate cause of what it has brought about. That is, to the extent that the behaviour of the thing is a result of the essence of the mode being expressed - to the extent that the behaviour comes from the thing itself, and nothing else - that mode is acting. By contrast, to the extent that the mode's behaviour is a result of it being acted on by other modes - that is, its behaviour is caused by something that lies outside itself - then it is passive.

For Spinoza, activity and freedom amount to the same thing. That is, to the extent that a mode is active it is free, and to the extent that it is passive it is unfree. Freedom for Spinoza therefore has nothing whatsoever to do with the will. After all, all modes, including non-conscious and inanimate ones, can be said to be more or less active depending on their circumstances. It is perfectly sensible, for Spinoza, to describe a rock or a tree as more or less free.

Similarly, when a mode expresses its essence, it is not doing so as a cause of itself in the sense of generating action out of nothing. Spinoza's picture is fully deterministic. Nevertheless, modes are all, by definition, conceived through things outside themselves. 
Hence, no mode has an essence that is totally given to it by itself. They do not exist "from the necessity of [their] nature alone" (Spinoza 1994, 1d7). Being "necessarily causally dependent on other things" (Kisner 2011, 44-5), the freedom of modes is only ever partial.

All modes attempt to express their essence to the maximum degree possible, e.g., they try to increase their power and the degree to which they are active. This is what Spinoza refers to as a thing's 'conatus.' In fact, according to Spinoza, conatic striving is "nothing but the actual essence of the thing" (1994, 3p7).

Though we use the term 'strive' to describe the conatus, this again does not mean that there is any kind of intentionality involved. All modes, whether conscious or unconscious, animate or inanimate, have a conatus, and thus 'strive' to persevere in their being. Striving is instead best thought of as a thing's natural tendency. Just as an object in motion will continue to move unless something else acts on it to cause it to stop, so will all modes naturally express their characteristic essence, unless something external acts on them to prevent it. Of course, human beings, as particularly complex modes, strive in particularly complex ways and, what is more, are aware of their striving. But the striving is our natural tendencies, rather than our awareness of those tendencies.

The conatus is fundamental to Spinoza's ethics. To call something 'good' is merely to say that it has supported our conatic striving, in that it has increased our power to express our essence. By contrast, 'bad' or 'evil' is merely whatever does the opposite. In this sense, then, these basic evaluative terms are relative to the individual. Nothing is inherently good or bad. Rather, something that is bad for me may be good for you, and there is no external perspective from which to come to a more objective judgement about that thing.

Nevertheless, whether something is good or bad for me is not subjective, in the sense of 'up to me,' but is rather an objective fact of the world. As Beth Lord puts it, moral values are "immanent to the individual's essence," and are therefore "real and true," since "for each individual, there are things that are truly good which promote its being, and things that are truly evil which detract from it" (Lord 2010, 107).

Virtue, for Spinoza, is nothing more than a person's ability to increase their power. As such, the more powerful we are, the more virtuous we can be said to be. In fact, for Spinoza,

By virtue and power I understand the same thing, that is, virtue, insofar as it is related to man, is the very essence, or nature, of man, insofar as he has the power of bringing about certain things, which can be understood through the laws of his nature alone (1994, 4d8).

Hence,

The more each one strives, and is able, to seek his own advantage, that is, to preserve his being, the more he is endowed with virtue; conversely, insofar as each one neglects his own advantage, that is, neglects to preserve his being, he lacks power $(1994,4 \mathrm{p} 20)$. 
To be free is to be the cause of one's actions; to be the cause of one's actions is to have power; and to have power is to be virtuous. Goodness is then nothing more than what brings about our freedom/power/virtue.

It is quite possible, however, for an individual to misidentify what is good for them. For this reason, knowledge - and particularly the possession of what Spinoza calls 'adequate ideas' - is an essential component of freedom/virtue/power. To have an adequate idea is have a genuine possession of the idea of something as a thought object. It is to have certain knowledge, to know something "fully and truly, through reason" (Lord 2010, 106). If we have an adequate idea of something, we can then be sure that it is good or bad for us, because we know, through our knowledge of its causes, what that thing truly can and cannot do. Inadequate ideas, by contrast, are when we do not have knowledge of a thing through that thing as a thought object, but rather through how it has acted on us (thereby increasing our passivity).

Adequate ideas therefore do not merely lead to an increase in power but are increase in power in and of themselves. Adequate ideas are those that are wholly a result of our own power of reason, and as such are caused by our own minds. In other words, merely having adequate ideas is to be, to that extent, the cause of ourselves, i.e., active and therefore powerful. To have inadequate ideas is to have our minds be caused by things other than ourselves, i.e., passive. This means that knowledge - like freedom and virtue - is quite literally power.

The ability to have adequate ideas - to know things in themselves through reason - gives us in turn what Spinoza calls 'common notions.' By knowing various things in themselves, we come to know their essences. By knowing their essences, we can then develop an understanding of just how different things assist or oppose one another.

A centrally important common notion in Spinoza is 'human nature.' Insofar as human beings share the same essence, their natures agree rather than disagree. This is because, in Spinoza's view, "No thing can be evil through what it has in common with our nature; but insofar as it is evil for us, it is contrary to us" (1994, 4p30). In other words, since our essences always tend towards our perseverance rather than dissolution, then nothing in our own natures can decrease our power or damage us. For Spinoza, essences always express their determinate power to act to the maximum extent possible. Only external things can limit or damage that power.

If two different modes share an essence, it is impossible that what Mode A shares with Mode B could ever be damaging to Mode B. Hence, Mode A's expression of that part of its essence can only ever be beneficial, and can never be harmful, to Mode B. In other words, insofar as we are similar, anything one human being does that is of benefit to them is also of benefit to all other human beings.

To the extent that we express our shared essence, then, human beings are beneficial to each other, even when acting purely out of self-interest. However, to the extent that we are acted on, i.e., we are passive, human beings can be harmful to one another. This is because passivity involves being made to behave by external causes, and external causes are almost inevitably going to differ from situation to situation. In other words, the more powerful we are - the more we can act to express our own essence - the more our actions will be in harmony with others. But the less powerful we are - the more our 
actions are caused by something outside ourselves - the more likely we will conflict with others.

For Spinoza, then, increasing our knowledge is perhaps the most significant thing we can do to promote virtue. In being the cause of ourselves due to our possession of adequate ideas, we will naturally - even if we do not intend it - act to benefit others while acting to benefit ourselves. Furthermore, the more we know, the better able we are to grasp the common notion of human nature. This allows us to act with others in such a way as to increase our power. The more rational we are, the more we unite with others in a composite body that can massively increase our collective power. Hence, the rational person will appreciate that behaviour that harms other human beings will harm themselves as well, and that behaviour that benefits others will also benefit themselves.

In short, while Spinoza's moral philosophy is built on self-interest, because of the common nature between all human beings genuine self-interest is identical to the best interests of others.

\subsection{CHAN ETHICS \& MORAL PHILOSOPHY}

In certain respects, Chan ethics offers precisely the opposite view to Spinoza. Rather than bringing us together, conceptualising things objectifies them, which give rises to attachment and leads to opposition. We treat things - including ourselves and other people - as having a self-nature, and in doing so we reify whatever aspect of those things that our conceptualisation of them has emphasised. We then inevitably relate to that aspect in a positive or negative way, i.e., we naturally see it as good for us or bad for us. Both are attachment: where we see something as good, we try to draw it to ourselves, and where we see it as bad, we oppose it. To put things in Spinozistic terms, by mistakenly seeing modes as having an essence, we inevitably classify everything as either having a positive or negative impact on our own essence and power and respond accordingly. For Chan, then, conflict arises because we fail to see that all things are empty. Ethics is therefore not a matter of tending to the essence of things; rather, it is seeing that they have no essence.

Instead of attaching ourselves to things via objectification, we ought to "engage freely with things" (Davis 2013, 202) by responding to them in their suchness. Things can only be considered good or bad for us insofar as we conceptualise them. If we refuse to do so, they are neither good nor bad: they are merely what they are. For this reason, Chan ethics transcends the concepts of right and wrong entirely. Good and evil are dualistic concepts, and like all concepts lead us to error.

Interestingly, Spinoza and Chan are not wholly dissimilar when it comes to good and evil. After all, Spinoza too believes that we are mistaken when we view things as good or evil in themselves. However, whereas for Spinoza this is because good and evil can only ever be relative to the individual, for Chan things cannot be good or evil in themselves because the terms themselves are meaningless. Something that is empty cannot be either good or evil, otherwise it would not truly be empty. Hence, Chan practitioners instead aim to "be emancipated from the existential antinomy of good and 
evil and to awaken to Emptiness prior to the opposition between good and evil" (Abe 1985, 132). Spinoza, by contrast, thinks that 'good' and 'evil' are meaningful terms, even if we can never describe anything as good or evil transcendentally.

Rejecting the meaningfulness of good and evil, however, does not lead to amorality. After all, to say that there is a 'me' who is separate from 'you' is to already fall into the trap of objectification. The self is itself a self-nature that emptiness denies. Hence, the realisation of emptiness at the same time breaks down the barrier between what is good for me and what is good for you. There is no me to ground self-interest in the first place.

We can say, then, that all things are "equal in their suchness" (Abe 1985, 208). Abe says that "everything is itself in the sense that everything is as it is, and yet at the same time, everything is equal in its as-it-is-ness" $(1985,208)$. In other words, comparison which hierarchy and differential treatment requires - is completely impossible if we refuse to objectify things. The only way I can say that Person A's interests are more significant than Person B's is if I am attributing to both a substance that allows Person A and Person B to be compared in some way. If both are empty, then Person A and Person B can only be absolutely, radically equal in their suchness.

\subsection{DISCUSSION}

The metaphysical systems of Spinoza and Chan are clearly reflected in their ethical philosophies, and this especially true in terms of their views on the idea of sameness.

For Spinoza, sameness is always relative. Because Spinoza sees essence as consisting in what lies behind a thing - that is, things are what they are conceived through - and because all things are an expression of substance through a particular lineage of finite causes, then comparison is possible. Given any two things, we can identify the extent to which their causes - and hence their essence - overlap.

Spinoza collapses the distinction between self- and other-interest, but he does this through an emphasis on what different things share. My good and your good align, for instance, insofar as we are the same. As a result, Spinoza's moral philosophy is wholly predicated on similarity. Of course, at the limit everything is an expression of substance, and therefore everything is the same. But when viewed from a less-than-ultimate perspective, the fundamental question of Spinoza's ethics is 'how much do we have in common?' We are in harmony to the extent that we are similar, and in conflict to the extent that we are not. Hence, for Spinoza similarity is the foundation of morality.

While Chan Buddhism shares with Spinoza the view that things gain their natures due to the causal/conceptual relations they have with other things, in Chan the 'interbeing' of all things - their dependent co-origination - vacates all things of essence. Since there is no grounding of the nature of things other than their mutual co-creation, there is ultimately nothing more to a thing than its suchness; its absolute uniqueness. As a result, everything is simultaneously both absolutely the same and absolutely different to everything else (to the extent that such terms are meaningful at all).

When it comes to Chan ethics, absolute sameness/difference leads to radical compassion and equality. The absolute nature of sameness and difference means that comparison between individuals is impossible. We cannot be described as either similar 
or different to each other. Lacking difference, there is no meaningful basis on which to treat one person's interests as more significant than another's. In fact, there is no meaningful distinction between 'me' and 'you' in the first place that would ground such an attitude. Hence, the enlightened Chan practitioner's attitude is one of radical compassion: they cannot even make sense of a 'good for me' than is distinct from a 'good for you.'

At the same time, absolute sameness/difference means, for much the same reason, that everything is radically equal to everything else. Everything is nothing more than what it is; nothing has an essence that would allow the kinds of comparisons that would ground differential concern.

\section{SAMENESS AND DIFFERENCE IN ENVIRONMENTAL PHILOSOPHY}

There is certainly some overlap between the metaphysics of Spinoza and Chan Buddhism. Both see the nature of a thing as consisting in that through which it is conceived. However, Spinoza's expressivist metaphysics - his uni-directional chain of conception - gives all things a unique individual essence; whereas the bi-directional conception of Chan dependent co-origination renders things wholly empty of essence. This in turn means that things for Spinoza can be meaningfully compared, whereas for Chan things, in their suchness, are both absolutely the same and absolutely distinct; or, to put things another way, the concepts of similarity and difference are transcended within Chan metaphysics.

One obvious place where the implications of Spinoza and Chan's divergent perspectives on sameness and difference becomes important is environmental philosophy. While Spinoza is very clear that it is in our best interests to advance the good of other human beings - that their good is our good - this claim is wholly grounded on the fact that human beings are similar enough to each other than our essences overlap. But at the same time, non-human animals - not to mention insentient life, ecosystems, and so on - are only of concern insofar as they benefit us. In other words, since non-human animals are beings quite different to us, then we are free to use them to increase our power, even when it is to the detriment of those animals.

Ironically then, the 'levelling' of Spinoza's philosophy - the claim that everything has a conatus and is therefore equal in its right to seek to increase its own power - ends up justifying the domination of nature. As Chandler D. Rogers puts it, Spinoza's ontological biocentrism leads of necessity to an axiological anthropocentrism (Rogers 2021). In Genevieve Lloyd's words, "The very recognition of man as part of nature that looks, at first sight, so promising as a basis for an environmental ethic, for Spinoza goes hand in hand with a reasoned acquiescence in the exploitation of other species" (Lloyd 1980, 294). That is, the very idea that beings exist for their own sakes, when situated in the context of Spinoza's ethics and metaphysics, entails that we can make no overall judgements about the good independent of any particular entity's perspective. This in turn means that we are justified in seeking our good at the expense of the good of other beings. For instance, if factory farming benefits us, then from Spinoza's point of view 
it is perfectly acceptable, irrespective of the implications for the non-human animals involved. In short, to the extent that animals differ in their essence from humans, Spinoza offers no grounds upon which we can assert that we ought to have any concern for them.

In fairness, this criticism of Spinoza can sometimes be overstated. After all, we are increasingly coming to understand that animals are not as different to us as we may have previously imagined. There is therefore almost certainly more of an overlap in essence between human beings and non-human animals than was recognised in Spinoza's time. If so, then by Spinoza's own lights we do have a good reason to act to promote the welfare of non-human animals. But the fact that remains this concern is always limited by relations of similarity. While nothing biotic is ever completely unlike us - all life shares an ancestor, after all - our concern for non-human entities ends precisely where our similarity does.

By contrast, Chan Buddhism seems to possess a more promising set of resources for grounding concern for the non-human world. However, it is important to be careful about precisely how we express that concern from a Chan perspective. For instance, putting the matter in terms of 'intrinsic value,' which is common in the environmental ethics literature, on the face of it seems to assume precisely the kind of self-nature that Chan Buddhists reject.

Similarly, dependent co-origination can and has been misappropriated by environmental philosophers in ways that are contrary to Chan thought. For example, the realisation of dependent co-origination might be understood as being something akin to the realisation of the interdependency of all life; the recognition that we are part of nature, rather than outside it; that our existence is unavoidably bound up with the existence of all other entities. As Joanna Macy puts it,

it would not occur to me to plead with you, 'Oh, don't saw off your leg. That would be an act of violence.' It wouldn't occur to me because your leg is part of your body. Well, so are the trees in the Amazon rain basin. They are our external lungs. And we are beginning to realize that the world is our body $(1990,69)$.

Understood in this way, dependent co-origination is equivalent to interconnection; the recognition that we are just one part of a greater whole. Since we are all interconnected, the argument goes, we ought to be just as concerned for the non-human world as with our selves, since the non-human world is part of our self in a very real sense.

But such an account of dependent co-origination mistakes internal relations for external ones. That is, the insight of dependent co-origination is not that what we do affects other things, and that what they do affects us in turn: it is not the recognition of ecological holism. Rather, it is that what we are is constituted by everything else (and vice versa). While the external relations view suggests that we should protect nature because it is part of our 'great Self' - our wider identification with the non-human world based upon the recognition of the connections between us - the internal relations view undermines this with the insight that there is no self to be extended in the first place. Our 'great Self' is just as empty as our small one. 
Second, while holists see the value of the parts as being derived from their contribution to the whole, the Chan Buddhist instead holds that "each being has a supreme worth as an embodiment of the whole" (James 2004, 75). Dōgen puts this in terms of being able to see "the entire world in one tiny speck of dust" $(1976,15)$. Hence, the enlightened person has concern with the non-human entities they encounter not because they are part of something bigger - that there is a whole to which they contribute - but rather because each part is the whole. In other words, the whole - the shifting network of internal relations that gives rise to each entity as a this - is in the parts, rather than the other way around. In a sense, this is precisely what is meant by transcending difference and similarity. For this reason, we can say that Chan displays a "dual commitment to holism and to the value of individual beings" (James 2004, 83). Via the internal relations between all things, every this constitutes every other this. In other words, everything is therefore valuable in and of itself, as an absolutely distinct this. But at the same time, every this is internally connected to every other this. Every entity is both absolutely different to every other, while also being absolutely the same.

But there is an issue here for Chan that is worth drawing attention to. If everything is both empty and internally related to everything else, then we have to wonder how we might ground moral concern at all. I have already mentioned, after all, that the emptiness of a thing entails that it cannot be either good or evil. Further, even if every entity is unique and valuable in its suchness, why prefer one state of affairs over another? As Marek Sullivan asks, "On what grounds are we to differentiate and privilege those aspects of reality we would like to see flourish against those we would not" $(2015,291)$ from a Chan perspective? Ian Harris puts it in the following way:

"since all things are interrelated we should act in a spirit of reverence towards them all" is to say little that is of any use to ethicists. For since "the category of 'all things"" includes insecticides, totalitarian regimes and nuclear weapons ... [the argument] suffers from a certain vacuity from the moral perspective $(1995,177)$.

Christopher Ives puts the problem in terms of "valorizing actuality" $(2013,563)$. Does Chan allow us to promote any kind of positive moral change? Can we work towards a state of affairs on the basis of it being an improvement on the current state of affairs? If not, then, as Harris puts it, it is "very hard to see how a specifically Buddhist position on global warming or on the decrease in diversity of species can be made" $(2014,126)$ and we might therefore question Chan's ability to follow through on its initial promise as an environmental ethic.

This criticism is certainly one that should be taken seriously. But Chan Buddhism is not without its responses. Firstly, it is often held that the central insight of enlightenment itself - that everything is empty - at the same time involves the adoption of what we can (from a non-enlightened perspective) describe as "moral virtues". The idea here is that insight into the emptiness of things and moral virtue is a "package deal" (James 2004, 128). This is also Damien Keown's view: acting wisely, compassionately and truthfully (for example) are integral to enlightenment itself (2001). In other words, "insight into emptiness does not constitute a merely intellectual understanding of the 
world; it is a form of practical wisdom which expresses itself in the way one sees the world and acts in it" (James 2004, 37).

We can see an example of this connection in terms of the values and behaviours that arise from attachment. Desire and greed arise from "craving things that we do not 'possess' and clinging to things we do 'possess"' (Ives 2013, 545). But for the Chan Buddhist, we only desire things because we take them to have a self-subsisting nature of their own and because we see ourselves as having a 'self' (James 2014, 101). But as Haku'un Yasutani points out, "Once you realize the world of [emptiness] you will readily comprehend the nature of the phenomenal world and cease clinging to it" (2011, 73). In transcending attachment - and the greed and desire that arise from - the Chan Buddhist therefore spontaneously ceases to treat nature in at least some of the more problematic ways identified by environmental philosophers. There is no longer any motivation to engage in acts of environmental degradation. Hence, while in principle any act can be performed in a Chan spirit, there is a reason why Chan enlightenment is usually associated with a simple lifestyle: the desire for material comforts or status is absent. In other words, enlightenment necessarily leads to a more ecologically sustainable form of life.

The same can be said of moral virtues such as non-violence and compassion. The enlightened person just naturally has compassionate concern for non-human entities, as she does with all things, and spontaneously acts in a non-violent way towards them. As James puts it,

The good Buddhist treats nature well... not because she believes she is 'one' with the natural world, but because she has, through practice, come to develop certain virtues of character. She treats nature well, that is, because she is compassionate, gentle, humble, mindful, and so on, not just in relation to her fellow humans, but in her dealings with all things $(2014,112)$.

Finally, moral quietism only appears to be compatible with Chan if we adopt the perspective of a Chan practitioner who is one step short of enlightenment. That is, disengaging with other entities - having no concern for anything - seems to correspond most closely to the second stage of insight, in which everything is seen as empty: the view that mountains are not mountains. In other words, moral quietism is a state of mind that valorises emptiness. The fully enlightened person, by contrast, "must resist being beguiled by emptiness but must open one's mind so that the world can, as it were, rush back in to fill the empty space of consciousness" (James 2004, 43). If we can realise that emptiness itself is empty - if we can reach the third stage in which we can appreciate that mountains are really mountains - we can engage with and attend to each thing as it is, spontaneously and without preconception.

In short, since the enlightened Chan Buddhist is not viewing things through the lens of same/different, then unlike in Spinoza's case there is no limit to what the enlightened person can attend to with compassion. The enlightened person does not weigh similarity and difference when deciding what she ought to do: it does not matter whether the chicken in the factory farm is like or unlike a human being. Rather, the 
Chan practitioner engages with each thing in terms of its suchness, and as a result acts to benefit it without preconception, attachment, or desire. Since virtues such as nonattachment, compassion and non-violence accompany the more theoretical insights of emptiness gained by a fully enlightened person, then of necessity such a person adopts of what we could perhaps describe (again, from a non-enlightened perspective) as a deep ecological environmental virtue ethics. Chan's realisation that things are neither different nor the same as one another - or, to put it another way, that they are absolutely the same and absolutely different - therefore allows for a concern for the non-human that is not found in Spinoza. Acting to benefit all things as the practitioner encounters them in their uniqueness is simply a natural, spontaneous practice generated by an enlightened perspective on the emptiness of all things (including the emptiness of emptiness itself).

\section{ACKNOWLEDGEMENTS}

I am very grateful to Rika Dunlap for her invaluable comments on an early draft of this paper, as well as for the contributions of the anonymous reviewers. I would also like to thank Gordon Davis, for prompting me to write on this topic in the first place.

\section{REFERENCES}

Abe, Masao (1985), Zen and Western Thought (London: MacMillan Press).

Abe, Masao (1997), Zen and Comparative Studies (London: Macmillan Press).

Davis, Bret W. (2013), "Forms of Emptiness in Zen", in Steven M Emmanuel (ed.), A Companion to Buddhist Philosophy (Wiley-Blackwell), 190-213<https://doi.org/ 10.1002/9781118324004.ch12>.

Della Rocca, Michael (2008), Spinoza (London, Routledge).

Della Rocca, Michael (2011), "Explaining Explanation and the Multiplicity of Attributes in Spinoza", in Michael Hampe, Ursula Renz \& Robert Schnepf (eds.), Spinoza's Ethics: A Collective Commentary (Leiden: Brill), 17-36 < https://doi.org/ 10.1163/ej.9789004194250.i-380.13>.

Dōgen (1976), Shōbōgenzō: The Eye and Treasury of the True Law, Vol. 1, translated by K. Nishiyama and J. Stevens (Tokyo: Nakayama Shobō).

Garfield, Jay L. (2009), "Nāgārjuna’s Mūlamadhyamakakārikā (Fundamental Verses of the Middle Way: Chapter 24: Examination of the Four Noble Truths", in William Edelglass and Jay L Garfield (eds.), Buddhist Philosophy: Essential Readings (Oxford: Oxford University Press), 26-34.

Harris, Ian (1995), "Getting to Grips with Buddhist Environmentalism: A Provisional Typology", Journal of Buddhist Ethics 2: 173-190.

Harris, Ian (2014), “Causation and 'Telos': The Problem of Buddhist Environmental Ethics", in J. Baird Callicott and James McRae (eds.), Environmental Philosophy in Asian Traditions of Thought (Albany: SUNY Press), 117-129. 
Huineng, Hui-neng's Commentary on the Diamond Sūtra, trans. Thomas Cleary (1998), The Sutra Of Hui-Neng, Grand Master Of Zen (Boston: Shambala).

Huineng, The Platform Sutra, trans. Philip B Yampolsky (2012), The Platform Sutra of the Sixth Patriarch. The Text of the tun-huang manuscript (New York, Columbia University Press).

Ives, Christopher (2013), "Resources for Buddhism Environmentalism", Journal of Buddhist Ethics 20: 541-571.

James, Simon P. (2004), Zen Buddhism and Environmental Ethics (Burlington VT: Ashgate Publishing Company).

James, Simon P. (2014), “Against Holism: Rethinking Buddhist Environmental Ethics", in J. Baird Callicott and James McRae (eds.), Environmental Philosophy in Asian Traditions of Thought (Albany: SUNY Press), 99-115.

Keown, Damien (2001), The Nature of Buddhist Ethics (Basingstoke: Palgrave).

Kisner, Matthew J. (2011), Spinoza on Human Freedom: Reason, autonomy and the good life (Cambridge: Cambridge University Press).

Lloyd, Genevieve (1980), "Spinoza's environmental ethics", Inquiry: An Interdisciplinary Journal of Philosophy 23.3: 293-311<https://doi.org/10.1080/ 00201748008601910>.

Lord, Beth (2010), Spinoza's Ethics: An Edinburgh Philosophical Guide (Edinburgh: Edinburgh University Press).

Macy, Joanna (1990), "The Greening of the Self", in Allan Hunt Badiner (ed.), Dharma Gaia: A Harvest of Essays in Buddhism and Ecology (Berkeley, California: Parallax Press).

Rogers, Chandler D. (2021), "Being consistently biocentric: on the (im)possibility of Spinozist animal ethics", Journal for Critical Animal Studies 18.1: 52-72.

Siderits, Mark and Shōryū Katsura (2013), Nāgārjuna's Middle Way: Mūlamadhyamakakārikā (Somerville: Wisdom Publications).

Sullivan, Marek (2015), "Nature's No-Thingness: Holistic Eco-Buddhism and the Problem of Universal Identity", Journal of Buddhist Ethics 22: 285-317.

Yasutani, Haku'un (2011), "Commentary on the Koan Mu", translated by Philip Kapleau, in James Ishmael Ford and Melissa Myozen Blacker (eds.), The Book of Mu: Essential Writings on Zen's Most Important Koan (Boston: Wisdom Publications), 71-81. 